\title{
Application of Carbonization Technique for Tire Waste Recycle
}

Go Takahashi ${ }^{1}$, Masaaki Takahashi ${ }^{2 *}$, Yukimasa Takemoto ${ }^{2}$,Masayoshi Okui ${ }^{3}$, Nariyoshi Shirahige ${ }^{4}$, Katsumi Iida $^{5}$ and Kunihiko Sato ${ }^{6}$

1. Sankoutuusyou Corporation, Nishiakuragawa 1739-26, Yokkaichi, Mie, Japan

2. Yokkaichi university, Kayou-cho 1200, Yokkaichi, Mie, 512-8512 Japan

3. Itochu EnexHome Life Corporation, Sekohigashi 1-1609, Moriyama ward, Nagoya, Japan

4. ShirahigeCorporation, Gokashoura 3833, Minami-Isecho, Mie, Japan

5. Kassui Plant Corporation, Akosucho 4-7, Yokkaichi, Mie, Japan

6. Mie Pref. Government, Waste Disposal Survaillance Division, Komeityo13, Tsu, Mie, Japan

\begin{abstract}
Tire waste is discharged at 3 or 4 million wheels per year in Japan. Tire waste is mainly treated as an auxiliary fuel in some cement kilns. However, significant amounts of tire waste is illegally discharged in dumping sites, and causing an environmental pollution. In order to find a practical recycling method of this tire waste, a carbonization technique was investigated. Tire waste was heated at 300 degrees for $3 \mathrm{~h}$. The tire was completely decomposed to gas, oil, charcoal and steel iron. The generated gas was separated in an oil separator, and incinerated as supplementary fuel. Generated oil was also separated in an oil separator and collected. The quality of the oil corresponded to kerosene or light oil can be used as a fuel.
\end{abstract}

Key words: Carbonization technique, tire waste, recycle.

\section{Introduction}

Many carbonization techniques have been developed, and introduced inorganic waste recycling [1]. Almost all of them aim at recovery of charcoal. Recently, gasification has been introduced in the carbonization technique, and a recovery of hydrogen or fuel oil from poly-hydrocarbon waste is ongoing [2-4].

Tire waste is discharged at 3 or 4 million wheel per year in Japan. Tire waste is mainly treated as an auxiliary fuel in some cement manufacture plants. However, effective recycling techniques have not been developed, significant amounts of tire waste is illegally discharged in dumping site, and causing environmental pollution. Tires are mainly made of hydrocarbon, carbon powder and iron wire, therefore, oil and charcoal can be recovered easily by heat treatment or

*Corresponding author: Masaaki Takahashi, researcher, research field: environmental technology. E-mail: machaaki@amigo.ne.jp. carbonization.

Katsumi [5] has designed a mobile middle size carbonization furnace which can recover charcoal and oil, and also can be transported to every site in where needed (Fig. 1). Introduction of the carbonization techniques to the tire recycling [6] has been investigated, however, in order to find a way of practical use, much information about the operating conditions or properties of charcoal or oil which are recovered from tire must be collected.

In order to confirm the properties of the recovered materials like gas, oil and charcoal, carbonization, which are investigated using the pilot study type of carbonization equipment.

\section{Methods}

The equipment (Fig. 2) is made up of a carbonization furnace which is combined with an oven drum (diameter $80 \mathrm{~cm}$, length $100 \mathrm{~cm}$ ), a gas-liquid 


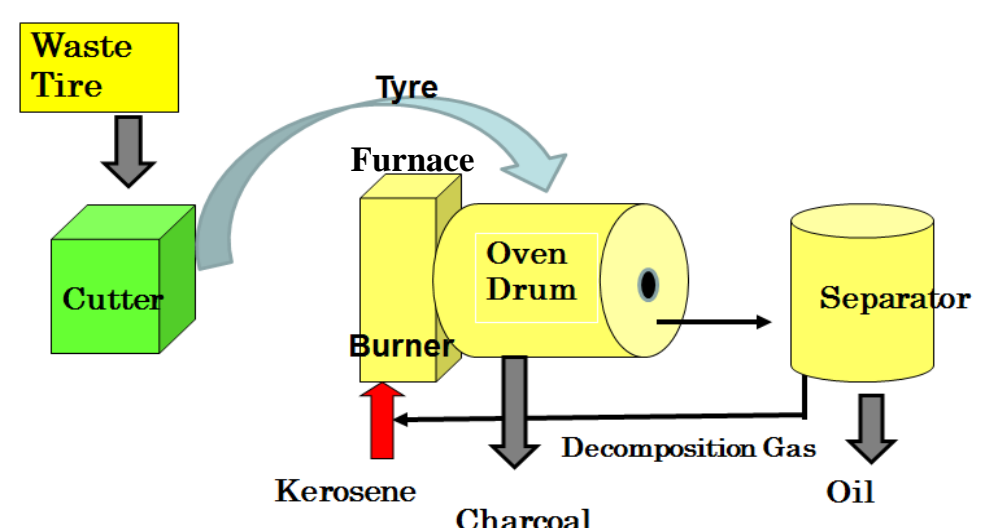

Fig. 1 Carbonization equipment.

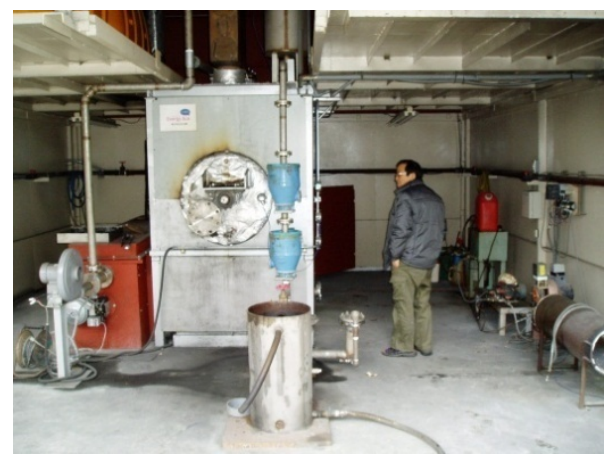

Fig. 2 Carbonization furnace.

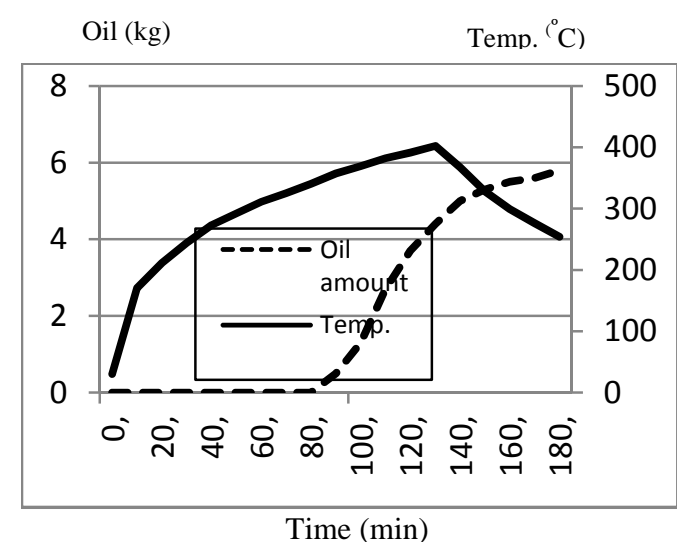

Fig. 3 Temp. dependence of the recovered oil.

separator and a burner. The oven drum contains a blade which is attached at the central shaft, and the blade rotates 10 cycles per min. by electric power. The burner is employed by kerosene combustion, can heat up the oven drum to a high temperature $\left(\max 500{ }^{\circ} \mathrm{C}\right)$. The oven drum is operated in aerobic low pressure $(-1,000 \mathrm{PaG})$, by air pump, and after treatment, charcoal is taken out from takeout hole which is attached below the drum. The recovered oil can be taken out from gas-liquid separator. Gas which is generated by carbonization is fed by air compressor to the burner, and used for generating the heat of carbonization. Maximum treatment capacity of this equipment is $30 \mathrm{~kg}$ in one batch process.

In this experiment, $20 \mathrm{~kg}$ of tire waste was cut to a size of about $10 \mathrm{~cm}$, put into the oven drum, and heated by kerosene burner. Temperature of the furnace is rising with time, after about $100 \mathrm{~min}$. oil was generated when temperature reached $350{ }^{\circ} \mathrm{C} .3 \mathrm{~h}$ later, the amount of the oil generated from oven was decreased to almost zero, the treatment was finished as shown in Fig. 3.

In this treatment, tire waste was completely decomposed to gas, oil, charcoal and iron wire.

The gas separated in the gas-liquid separator, returned to the burner of the furnace, and was incinerated with kerosene as a fuel. Generated oil was also separated in a gas-liquid separator and flowed out from upper nozzle of the separator.

Charcoal which containing iron wire was taken out from the take-out hole of the oven drum.

Amount of the recovered materials is shown in Table 1.

\section{Results and Discussion}

The quality of the recovered oil (Fig. 4) was investigated, and the properties were as follows, specific density: 0.953 , flash temperature: $25.4{ }^{\circ} \mathrm{C}$, sulfur 
Table 1 Amount of the recovered materials.

\begin{tabular}{lllll}
\hline Waste tire & Charcoal & Oil & Iron wire & Gas* \\
\hline 18.4 & 6.4 & 6.6 & 1.7 & 3.7 \\
\hline
\end{tabular}

Unit; kg.

* Estimated from mass balance.

Table 2 Property of the recovered oil.

\begin{tabular}{clll}
\hline Item & Specific density & Apparent viscosity & Flash temp. \\
\hline Data & 0.953 & $6.30 \mathrm{~mm}^{2} / \mathrm{s}$ & $25.4^{\circ} \mathrm{C}$ \\
Item & Total Sulfur & $\begin{array}{l}\text { Remained carbon } \\
(10 \%)\end{array}$ & Pour point \\
Data & $0.66 \%$ & $31.4 \%$ & $-20{ }^{\circ} \mathrm{C}$ \\
\hline
\end{tabular}

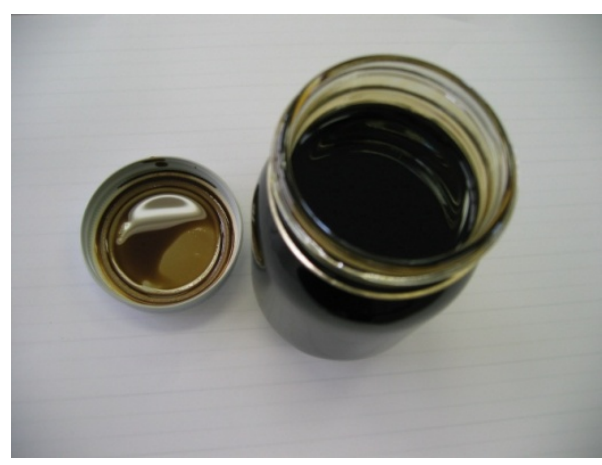

Fig. 4 Recovered oil.

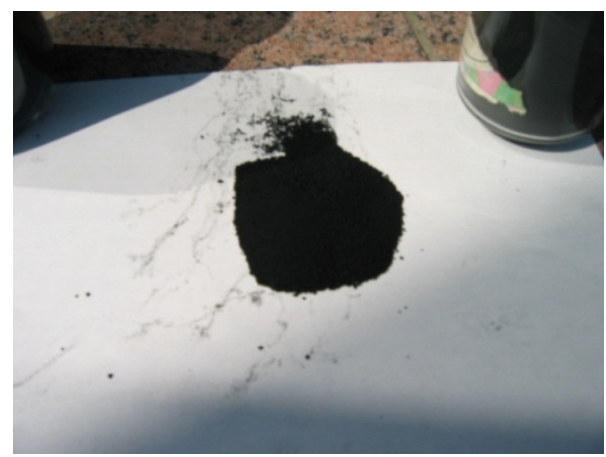

Fig. 5 Recovered charcoal.

Table 3 Particle size of the recovered charcoal.

\begin{tabular}{llllll}
\hline Size & $<$ & 0.075 & 0.15 & 0.3 & 1 \\
$(\mathrm{~mm})$ & 0.075 & -0.15 & -0.3 & -1 & -3 \\
\hline$\%(\mathrm{w} / \mathrm{w})$ & 12 & 13 & 53 & 19 & 3 \\
\hline
\end{tabular}

Table 4 The ash composition of the charcoal.

\begin{tabular}{llllll}
\hline $\mathrm{ZnO}$ & $\mathrm{CaO}$ & $\mathrm{Fe}_{2} \mathrm{O}_{3}$ & $\mathrm{SiO}_{2}$ & $\mathrm{SO}_{3}$ & $\mathrm{X}$ \\
\hline 55 & 8 & 2 & 15 & 11 & 9 \\
\hline
\end{tabular}

$\mathrm{X}$ : Others.

Unit: \%.

Ash content of the charcoal: $8.2 \%$.

content: $0.66 \%$, pour point: -20 degree (Table 2), and heat of combustion is $43.5 \mathrm{~J} / \mathrm{Kg}$. Property of the oil corresponds to kerosene or light oil, and is regarded to be an auxiliary fuel for boiler or automobile oil, however, high total sulfur was found, and removal of the sulfur seems to be needed.

The recovered charcoal (Fig. 5) was black powder, particle size distribute almost under $1 \mathrm{~mm}$ (Table 3), and incinerated for investigation at $700{ }^{\circ} \mathrm{C}$. The ash content of the charcoal was $8.2 \%$, and analyzed using X-ray florescent analyzer, and elemental composition of the ash was shown in Table 4, and high concentration of $\mathrm{ZnO}$ was found. Some studies to make an absorbent from charcoal are ongoing [7], however, usage of the zinc raw material was expected to be better from the stand point of high zinc content.

Iron wire is easily recycled in usual recycling methods.

$4.6 \times 10^{8} \mathrm{~J}$ of energy (electric and kerosine) is estimated to make up a temp. which is needed to maintain the carbonization (tire $20 \mathrm{~kg}$ ). This furnace is operated discontinuously, therefore, the heat to maintain the reaction will be lost between operations. Adopting a continuous operation method [8], this energy loss will be prevented, and almost all energy which is needed to make carbonization, is supplied by combustion of decomposition gas except for electric power. Therefore, this technique will be a suitable method for energy recovery and also resource recovery.

\section{Conclusions}

In order to find a method for tire waste recycling, a carbonization technique has been investigated. Charcoal, oil, iron wire are recovered from waste tire by this method. The recovered oil is considered to be useful as a fuel of boiler or automobile, however, removal of sulfur or other contaminants are thought to be needed. The charcoal is also possible material for a zinc refinery, but more information about the chemical state of the zinc and the physical properties of the charcoal is needed in order to be a practical raw material in zinc industries. 


\section{References}

[1] JEF Engineering Corporation. 2004. "JFE Waste Carbonizing System.” JFE Technical Report.

[2] Otaka, M., Ichikawa, K., Tanaka, K., Shoji, T. and Matsui, T. 2010. "Development of Biomass Carbonizing Gasification Technology -Gasification Performance of Sewage Sludge Compost-”, CRIEPI Research Report. M 10023

[3] Wei, W., Kawamoto, K. and Kuramochi, H. 2006. "Hydrogen-Rich Synthesis Gas Production from Waste Wood via Gasification and Reforming Technology for Fuel Cell Application”, Journal of Material Cycles and waste management 8: 70-7.

[4] Wei, W., Kawamoto, K. and Kuramochi, H. 2006. "Hydrogen-Rich Gas Production from RPF via Gasification and Reforming Technology”, In Proceedings of $17^{\text {th }}$ Annual Conference of the Japan Society of Waste Management Experts, 737-9.
[5] Okui, M., Nariyoshi, S., Kaztumi, I., Kunihiko, S., Hideo E. and Masaaki, T. 2005. "Carbonization Method of Tyre Waste Recycle”, In Proceedings of $16^{\text {th }}$ Annual conference of the Japan Society of Waste Management Experts, 695-6.

[6] Takahashi, M., Okui, M., Shirahige, N., Iida, K. and Sato, K. 2007. "Application of Carbonization Technique for Tyre Waste Recycle”, In Proceedings of $6^{\text {th }}$ Asia Pacific Conference on Sustainable Energy and Environmental Technology (APCSEET).

[7] Yamaguchi, K., Kinoshita, T., Akita, S., Hayashi, H. and Hirano, K. 2006. "Production of Activate Carbon from Ash of Waste Tire and Poly-vinyl Chloride Mixture via Thermal Treatment", In Proceedings of $17^{\text {th }}$ Annual Conference of the Japan Society of Waste Management Experts 565-7.

[8] JFE Engineering Corporation .2005. "Engineering News Release.” JFE Apr 19. 